\title{
KORELASI PENERIMAAN ORANGTUA TERHADAP STRES PENGASUHAN DALAM MERAWAT ANAK RETARDASI MENTAL: EFEK MEDIASI HARGA DIRI ORANGTUA (Studi Di SDLB Bhakti Luhur Kota Malang)
}

\author{
Yeni Fitria \\ (Universitas Jember, Fakultas Keperawatan, yeni.fitria040@gmail.com) \\ Sri Poeranto \\ (Universitas Brawijaya, Fakultas Kedokteran, Program Studi Pendidikan Dokter) \\ Lilik Supriati \\ (Universitas Brawijaya, Fakultas Kedokteran, Program Studi llmu Keperawatan)
}

\begin{abstract}
ABSTRAK
Hambatan kognitif dan fungsi adaptif pada anak retardasi mental menjadi stressor bagi orangtua, karena dalam perawatannya perlu penanganan khusus. Kondisi tersebut berdampak pada penerimaan orangtua terhadap anak dan pada harga diri orangtua, yang akhirnya dapat menyebabkan stress pengasuhan. Tujuan penelitian ini yaitu untuk menganalisis efek harga diri orangtua sebagai faktor mediasi antara penerimaan orangtua terhadap stres pengasuhan dalam merawat anak retardasi mental. Rancangan penelitian menggunakan analitik korelasi dengan pendekatan cross sectional, menggunakan purposive sampling dengan jumlah 43 responden. Instrumen penelitian yang digunakan yaitu Parental Acceptance Rejection Questionnaire/ (PARQ), Brief Self Esteem Inventory/ (BSEI) dan Parenting Stres Index Short Form/ (PSI-SF). Analisis jalur (path analysis) digunakan sebagai uji statistik. Hasil penelitian menunjukkan bahwa ada hubungan tidak langsung antara penerimaan orangtua dengan stres pengasuhan melalui efek mediasi harga diri orangtua. Besar hubungan tidak langsung antara penerimaan terhadap stress pengasuhan melalui harga diri orangtua adalah sebesar $2,92 \%$. Kurangnya penerimaan terhadap anak retardasi mental menyebabkan orangtua memiliki harga diri rendah, yang berdampak timbulnya stress pengasuhan.
\end{abstract}

Kata Kunci: Penerimaan orangtua, harga diri orangtua, stres pengasuhan, retardasi mental

\begin{abstract}
Cognitive impairments and adaptive functions in mental retardation children become stressors for parents, because in their care need special treatment. These conditions have an impact on parents 'acceptance of the child and on the parents' self-esteem, which can ultimately cause parental stress. The research objective is to analyze the effects of parental self-esteem as a mediating factor between parental acceptance of parental stress in caring for children with mental retardation. This study used a correlation analytic design with a cross sectional approach, using purposive sampling with a total of 43 respondents. The research
\end{abstract}


instruments used were Parental Acceptance Rejection Questionnaire / (PARQ), Brief Self Esteem Inventory / (BSEI) and Parenting Stress Index Short Form / (PSI-SF). Path analysis is used as a statistical test. The results showed that there was an indirect relationship between parental acceptance and parental stress through the mediation effect of parental self-esteem. The amount of indirect relationship between acceptance of parental stress through parental self-esteem is $2.92 \%$. Lack of acceptance of children's mental retardation causes parents to have low self-esteem, which results in the stress of parenting.

Keywords: Parental acceptance, parental self esteem, parenting stress, mental retardation

\section{PENDAHULUAN}

Salah satu masalah kesehatan jiwa yang sering terjadi pada masa anak dan remaja adalah retardasi mental. Populasinya memiliki angka paling besar jika dibandingkan dengan populasi keterbatasan lainnya. Secara global angka prevalensi retardasi mental yaitu 10,37/1000 populasi (maulik, et.al., 2011). Prevalensi retardasi mental diprediksi sebanyak $1 \%-3 \%$ populasi dan $85 \%$ merupakan retardasi mental ringan. Sedangkan retardasi mental sangat berat hanya sekitar 1-2\%. Insiden tertinggi pada anak usia sekolah, dengan usia puncak 10-14 tahun. Pada Angka mortalitas yang tinggi terjadi pada retardasi mental sangat berat sebagai akibat dari komplikasi terkait dengan kondisi fisik (Sadock \& Sadock, 2010).

Dampak merawat anak retardasi mental bagi keluarga dirasakan cukup besar, baik secara fisik maupun psikologis, meskipun sebagian besar retardasi mental merupakan kasus ringan. Namun dampak tersebut kurang mendapat perhatian dari tenaga kesehatan. Hal ini ditunjukkan dari studi yang menyatakan bahwa dukungan tenaga kesehatan bagi orangtua dengan anak retardasi mental masih kurang (Glenn,
2014). Menurut Tavakolizadeh (2012), memiliki anak retardasi mental juga dapat berdampak pada kesehatan mental orangtua, terutama bagi ibu. Orantua dengan retardasi mental rentan mengalami stress, ansietas, dan depresi (Lee, 2013). Sebuah studi oleh Woodman, et al., (2015) dan Craig, et al. (2016), memperlihatkan bahwa orangtua anak retardasi mental mengalami stress pengasuhan apabila dibandingkan dengan orangtua anak yang normal. Penelitian ini juga menunjukkan adanya hubungan timbal balik antara stress pengasuhan dengan perilaku anak retardasi mental.

Merawat anak disabilitas menimbulkan beban subjektif, salah satunya adalah stigma social (McNally \& Mannan, 2013; Cantwell, 2015). Orangtua merasa takut untuk membawa anaknya keluar dimasyarakat untuk melindungi anak dari stigma (Elford, 2015). Hal ini potensial berdampak pada dukungan social, harga diri, dan kesehatan psikologis. Orangtua dengan harga diri positif memiliki resiliensi dan kesehatan psikologis yang lebih baik (Bekhet, et al, 2012). Studi oleh Cantwell (2015), memperlihatkan bahwa orangtua dengan harga diri rendah cenderung mengalami gejala 
depresi. Menurut Stuart (2013) harga diri merupakan penilaian individu terhadap dirinya melalui analisis kesesuaian antara perilaku dengan ideal diri.

Harga diri menjadi mediator antara penerimaan atau penolakan orangtua dengan timbulnya depresi (Kockar, 2006). Menurut Onder \& Gulay (2010) orangtua anak retardasi mental menunjukkan tingkat penolakan yang lebih tinggi dibandingkan orangtua anak normal. Hal ini disebabkan akibat disabilitas perkembangan, masalah psikologis, sosial ekonomi, dan masalah lain yang muncul pada keluarga dengan anak disabilitas, sehingga berdampak pada tingkat penerimaan orangtua terhadap anak (Aydin \& Yamac, 2014).

Berdasarkan hasil studi pendahuluan terhadap 10 responden yang dilakukan di Sekolah Dasar Luar Biasa (SDLB) Bhakti Luhur, diperolah data kualitatif bahwa semua responden merasa sedih, syok, dan tidak percaya saat mengetahui diagnosis anaknya, serta ada rasa khawatir akan masa depan anak karena anaknya memiliki keterbatasan dalam hal kemandirian. Sebanyak 8 responden malu dan merasa rendah diri akibat keadaan anaknya. Sebanyak 5 responden merasa dijauhi oleh lingkungannya. Sebanyak 7 responden mengalami stres selama merawa anak.

Penelitian ini bertujuan untuk menganalisis efek harga diri orangtua sebagai faktor mediasi antara penerimaan orangtua terhadap stres pengasuhan merawat anak retardasi mental di SDLB Bhakti Luhur Kota Malang.

\section{METODE PENELITIAN}

Rancangan penelitian yang digunakan adalah analitik korelasional dengan pendekatan cross sectional. Dengan menggunakan teknik purposive sampling diperoleh sampel sebanyak 43 responden. Populasi dan sampel penelitian ini adalah orangtua anak retardasi mental yang bersekolah di SDLB Bhakti Luhur kelas $1-6$. Instrumen penelitian yang digunakan yaitu Parental Acceptance Rejection Questionnairel PARQ, Brief Self esteem Inventory/ BSEI, dan Parenting Stres Index Short Form/ PSI-SF. Uji korelasi pearson dan analisis jalur (path analysis) digunakan sebagai uji statistik. Penelitian ini telah memperoleh kelayakan etik dari Poltekes Kemenkes Malang.

Secara teoritis hubungan antar variabel dapat dibuat dalam bentuk diagram jalur seperti pada gambar 1 .

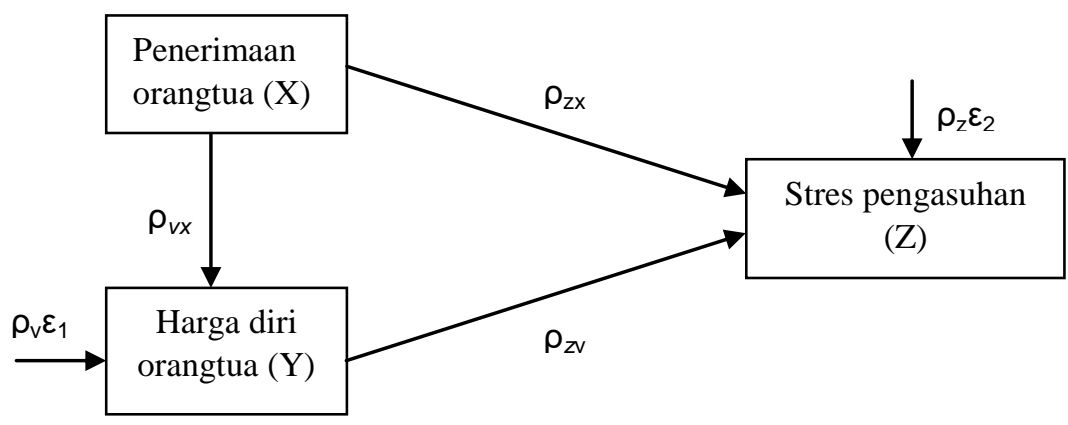

Gambar 1. Diagram Jalur Model Teoritis Penelitian 
Gambar 1 menunjukkan bahwa terdapat dua jalur hubungan antar variabel. Jalur pertama menggambarkan analisis jalur dari variabel penerimaan terhadap harga diri orangtua. Sedangkan jalur kedua menggambarkan analisis jalur dari variabel penerimaan dan harga diri orangtua terhadap stres pengasuhan. Gambar diatas dapat dinyatakan dalam bentuk persamaan struktur model sebagai berikut:

Struktur Jalur 1: $\mathrm{Y}_{\text {Harga diri orangtua }}=\rho_{\mathrm{yx}}$ $\mathrm{X}+\rho_{\mathrm{y}} \varepsilon_{1}$

Struktur Jalur 2: $Z_{\text {Stres pengasuhan }}=\rho_{\mathrm{zx}}$ $\mathrm{X}+\rho_{\mathrm{zy}} \mathrm{Y}+\rho_{\mathrm{z}} \varepsilon_{2}$

\section{HASIL PENELITIAN}

Tabel 1. Karakteristik Anak Berdasarkan Usia

\begin{tabular}{lcccccc}
\hline No & Karakteristik & n & Mean & Median & $\begin{array}{c}\text { Minimum - } \\
\text { Maksimum }\end{array}$ & $\begin{array}{c}\text { Standar } \\
\text { deviasi }\end{array}$ \\
\hline 1 & Usia & 43 & 11,86 & 12 & $7-20$ & 2,765 \\
\hline
\end{tabular}

Sumber: data primer, 2016

Tabel 2 Karakteristik Anak Berdasarkan Tingkat Retardasi Mental

\begin{tabular}{|c|c|c|c|}
\hline No & Karakteristik & Frekuensi & Prosentase \\
\hline 1 & Tingkat Retardasi Mental & & \\
\hline & a. RM Ringan & 9 & $21 \%$ \\
\hline & b. RM Sedang & 22 & $51 \%$ \\
\hline & c. RM Berat & 12 & $28 \%$ \\
\hline
\end{tabular}

Sumber: data primer, 2016

Tabel 3 Karakteristik Orangtua Berdasarkan Usia

\begin{tabular}{llccccc}
\hline No & Karakteristik & $\mathbf{n}$ & Mean & Median & $\begin{array}{c}\text { Minimum - } \\
\text { Maksimum }\end{array}$ & $\begin{array}{c}\text { Standar } \\
\text { deviasi }\end{array}$ \\
\hline 1 & Usia & 43 & 41,3 & 41 & $28-62$ & 7,567 \\
\hline
\end{tabular}

Sumber: data primer, 2016

Tabel 4 Karakteristik Orangtua Berdasarkan Orangtua yang Dominan Merawat Anak, Pendidikan, Pekerjaan, Penghasilan Keluarga, Jumlah Anak, dan Status Perkawinan

\begin{tabular}{|c|c|c|c|}
\hline No & Karakteristik & Frekuensi & Prosentase \\
\hline \multirow[t]{3}{*}{1} & Orangtua yang Dominan Merawat Anak & & \\
\hline & a. Ayah & 7 & $16 \%$ \\
\hline & b. Ibu & 36 & $84 \%$ \\
\hline \multirow[t]{5}{*}{2} & Pendidikan & & \\
\hline & a. $\mathrm{SD}$ & 11 & $25 \%$ \\
\hline & b. SMP & 15 & $35 \%$ \\
\hline & c. $\mathrm{SMU}$ & 12 & $28 \%$ \\
\hline & d. Diploma/ Sarjana & 5 & $12 \%$ \\
\hline \multirow[t]{3}{*}{3} & Pekerjaan & & \\
\hline & a. Bekerja & 15 & $35 \%$ \\
\hline & b. Tidak Bekerja & 28 & $65 \%$ \\
\hline \multirow[t]{3}{*}{4} & Penghasilan Keluarga & & \\
\hline & a. $\quad<1,8$ juta & 33 & $77 \%$ \\
\hline & b. $>1,8$ juta & 10 & $23 \%$ \\
\hline \multirow[t]{2}{*}{5} & Jumlah Anak & & \\
\hline & a. 1 orang & 10 & $23 \%$ \\
\hline
\end{tabular}




\begin{tabular}{clcc}
\hline b. $\quad 2$ orang & 22 & $51 \%$ \\
\hline \multicolumn{2}{c}{ c. $\quad=/>3$ orang } & 11 & $26 \%$ \\
\hline 6 & Status Perkawinan & & \\
\hline \multicolumn{2}{c}{ a. $\quad$ Kawin } & 38 & $88 \%$ \\
\hline b. $\quad$ Tidak kawin (Janda/Duda) & 5 & $12 \%$ \\
\hline
\end{tabular}

Sumber: data primer, 2016

Berdasarkan tabel 1 dan 2, diketahui bahwa rata - rata usia anak responden yaitu 11,86 tahun dan lebih dari setengah responden, yaitu 22 responden $(51 \%)$ memiliki anak dengan tingkat retardasi mental sedang.

Pada karakteristik responden (tabel 3,4) didapatkan data rata-rata usia responden yaitu 41,3 tahun. Sebagian besar responden yang dominan merawat anak adalah ibu yaitu 36 responden (84\%). Sebanyak 15 responden $(35 \%)$ memiliki tingkat pendidikan terakhir SMP. Lebih dari setengah responden, yaitu 28 responden $(65 \%)$ tidak bekerja. Sebagian besar responden, yaitu 33 responden (77\%) memiliki penghasilan keluarga kurang dari 1,8 juta Rupiah/bulan (dibawah Upah Minimum Regional). Lebih dari setengah responden, yaitu 22 responden $(51 \%)$ memiliki 2 anak. Sebagian besar responden, yaitu 38 responden $(88 \%)$ responden berstatus kawin.

Untuk data khusus penelitian dijabarkan dalam tabel 5.

Tabel 5 Deskripsi Variabel Penerimaan Orangtua, Harga Diri Orangtua, dan Stres Pengasuhan

\begin{tabular}{llccccc}
\hline No & \multicolumn{1}{c}{ Variabel } & n & Mean & Median & $\begin{array}{c}\text { Minimum - } \\
\text { Maksimum }\end{array}$ & $\begin{array}{c}\text { Standar } \\
\text { deviasi }\end{array}$ \\
\hline 1 & Penerimaan orangtua & 43 & 70,26 & 70,00 & $58-86$ & 8,021 \\
\hline 2 & Harga diri orangtua & 43 & 53,53 & 52,00 & $40-67$ & 6,819 \\
\hline 3 & Stres pengasuhan & 43 & 46,60 & 45,00 & $34-65$ & 7,835 \\
\hline
\end{tabular}

Sumber: data primer, 2016

Berdasarkan tabel 5 dapat dijelaskan bahwa pada variabel penerimaan orang tua didapatkan rata - rata skor sebesar 70,26 dengan nilai minimum 58 dan maksimum 86. Data ini menunjukkan bahwa semua responden termasuk dalam kategori penerimaan, artinya semua orangtua dapat menerima anak dengan retardasi mental. Pada variabel harga diri orang tua didapatkan rata - rata skor sebesar 53,53 dengan nilai minimum 40 dan maksimum 67. Berdasarkan data tersebut bisa disimpulkan bahwa rata - rata responden termasuk dalam kategori memiliki harga diri sedang. Pada variabel stres pengasuhan didapatkan rata - rata skor sebesar 46,60 dengan nilai minimum 34 dan maksimum 65. Data tersebut menunjukkan bahwa rata - rata responden termasuk dalam kategori normal, artinya responden tidak mengalami stres pengasuhan ketika merawat anak retardasi mental.

Hubungan Langsung Penerimaan Orangtua $(X)$ dengan Harga Diri Orangtua (Y) dalam Merawat Anak Retardasi Mental (Struktur Jalur 1)

Hasil uji hubungan penerimaan $(\mathrm{X})$ dengan harga diri orangtua $(\mathrm{Y})$ terlihat pada tabel 6 . 
Tabel 6. Hubungan Penerimaan (X) dengan Harga Diri Orangtua (Y) dalam Merawat Anak Retardasi Mental

\begin{tabular}{lcccccc}
\hline \multicolumn{1}{c}{ Variabel } & $\begin{array}{c}\mathbf{R} \\
\text { Square }\end{array}$ & Beta & $\mathbf{T}_{\text {hitung }}$ & $\mathbf{T}_{\text {tabel }}$ & $\mathbf{p ~ V a l u e}$ & Keterangan \\
\hline $\begin{array}{l}\text { Penerimaan } \rightarrow \\
\text { harga diri orangtua }\end{array}$ & 0,222 & 0,471 & 3,416 & 2,021 & 0,001 & Signifikan \\
\hline Surian
\end{tabular}

Sumber: data primer, 2016

Berdasarkan tabel 6 berhubungan langsung secara didapatkan bahwa nilai $\mathrm{p}$ value lebih signifikan dengan harga diri orangtua kecil dari $0,05(0,001<0,05)$, artinya dengan kontribusi sebesar $0,471^{2}$ atau variabel penerimaan orangtua $22,2 \%$.

Hubungan Langsung Penerimaan

Orangtua (X) dengan Stres Pengasuhan $(\mathbf{Z})$
Hasil uji secara langsung Penerimaan orangtua (X) dengan Stres Pengasuhan (Z) ditunjukkan pada tabel berikut:

Tabel 7. Hubungan Penerimaan Orangtua (X) dengan Stres Pengasuhan (Z) dalam Merawat Anak Retardasi Mental

\begin{tabular}{lcccccc}
\hline \multicolumn{1}{c}{ Variabel } & $\begin{array}{c}\mathbf{R} \\
\text { Square }\end{array}$ & Beta & $\mathbf{T}_{\text {hitung }}$ & $\mathbf{T}_{\text {tabel }}$ & p Value & Keterangan \\
\hline $\begin{array}{l}\text { Penerimaan } \rightarrow \\
\text { Stres Pengasuhan }\end{array}$ & 0,410 & $-0,383$ & $-2,779$ & 2,021 & 0,008 & Signifikan \\
\hline
\end{tabular}

Sumber: data primer, 2016

Berdasarkan tabel 7 didapatkan bahwa nilai $\mathrm{p}$ value lebih kecil dari $0,05(0,008<0,05)$, artinya variabel penerimaan orangtua berhubungan langsung secara signifikan dengan stres pengasuhan dengan kontribusi sebesar $-0,383^{2}$ atau $14,7 \%$.
Hubungan Langsung Harga Diri Orangtua (Y) dengan Stres Pengasuhan $(Z)$

Hasil uji secara langsung harga diri orangtua $(\mathrm{Y})$ dengan stres pengasuhan (Z) ditunjukkan pada tabel berikut:

Tabel 8. Hubungan Harga Diri Orangtua (Y) dengan Stres Pengasuhan (Z) dalam Merawat Anak Retardasi Mental

\begin{tabular}{lcccccc}
\hline \multicolumn{1}{c}{ Variabel } & $\begin{array}{c}\mathbf{R} \\
\text { Square }\end{array}$ & Beta & $\mathbf{T}_{\text {hitung }}$ & $\mathbf{T}_{\text {tabel }}$ & $\mathbf{p ~ V a l u e}$ & Keterangan \\
\hline $\begin{array}{l}\text { Harga Diri } \\
\text { Orangtua } \rightarrow \text { Stres } \\
\text { Pengasuhan }\end{array}$ & 0,410 & $-0,364$ & $-2,641$ & 2,021 & 0,012 & Signifikan \\
\hline Sunan & & & & & & \\
\hline
\end{tabular}

Sumber: data primer, 2016

Berdasarkan tabel 8 didapatkan bahwa nilai $\mathrm{p}$ value lebih kecil dari $0,05(0,012<0,05)$, artinya variabel harga diri orangtua berhubungan langsung secara signifikan dengan stres pengasuhan dengan kontribusi sebesar $-0,364^{2}$ atau $13,2 \%$. 
Hubungan Tidak Langsung antara Penerimaan Orangtua $(X)$ dengan Stres Pengasuhan (Z) melalui Pembentukan Harga Diri Orangtua (Y)

Pola hubungan tidak langsung adalah bagian koefisien jalur yang dapat dilacak secara kausalitas melalui variabel perantara. Prosedur yang biasa digunakan untuk menentukan besar hubungan tidak langsung yaitu dengan mengalikan koefisien jalur - koefisien jalur yang melewati variabel perantara pada hubungan antar variabel tersebut (Winarsunu, 2012). Dalam penelitian ini besar koefisien hubungan tidak langsung antara penerimaan orangtua dengan stres pengasuhan melalui pembentukan harga diri orangtua adalah sebagai berikut:

$$
\begin{aligned}
\rho_{\mathrm{xz}} & =\left(\rho_{\mathrm{yx}} \times \rho_{\mathrm{zy}}\right) \\
& =0,471 \times-0,364=0,171
\end{aligned}
$$

Berdasarkan perhitungan diatas maka estimasi besar hubungan tidak langsung antara penerimaan orangtua dengan stres pengasuhan melalui pembentukan harga diri adalah sebesar $0,171^{2}$ atau $2,92 \%$.

Koefisien Total atau Koefisien Jalur
Koefisien total menunjukkan hasil penjumlahan antara koefisien jalur hubungan secara langsung dengan koefisien jalur hubungan secara tidak langsung (Winarsunu, 2012). Dalam penelitian ini besar koefisien total hubungan langsung dan tidak langsung antara penerimaan orangtua, harga diri orangtua, dan stres pengasuhan adalah sebagai berikut:

$$
\begin{aligned}
r_{\mathrm{xz}} & =\rho_{\mathrm{zx}}+\left(\rho_{\mathrm{yx}} \times \rho_{\mathrm{zy}}\right) \\
& =-0,383+(0,471 \mathrm{x}-0,364) \\
& =-0,383+(-0,171) \\
& =-0,554
\end{aligned}
$$

Dari perhitungan diatas menunjukkan bahwa total hubungan yang dapat dijelaskan oleh penerimaan orangtua terhadap stres pengasuhan melalui harga diri orangtua sebesar $55,4 \%$. Sedangkan sisanya, sebesar 44,6\% dijelaskan oleh faktor - faktor lain yang tidak diteliti dalam model penelitian ini.

Menurut hasil pada koefisien jalur 1 dan jalur 2 maka secara keseluruhan hubungan kausal empiris antara variabel penerimaan orangtua, harga diri orangtua, dan stres pengasuhan dapat digambarkan seperti pada gambar 2 .

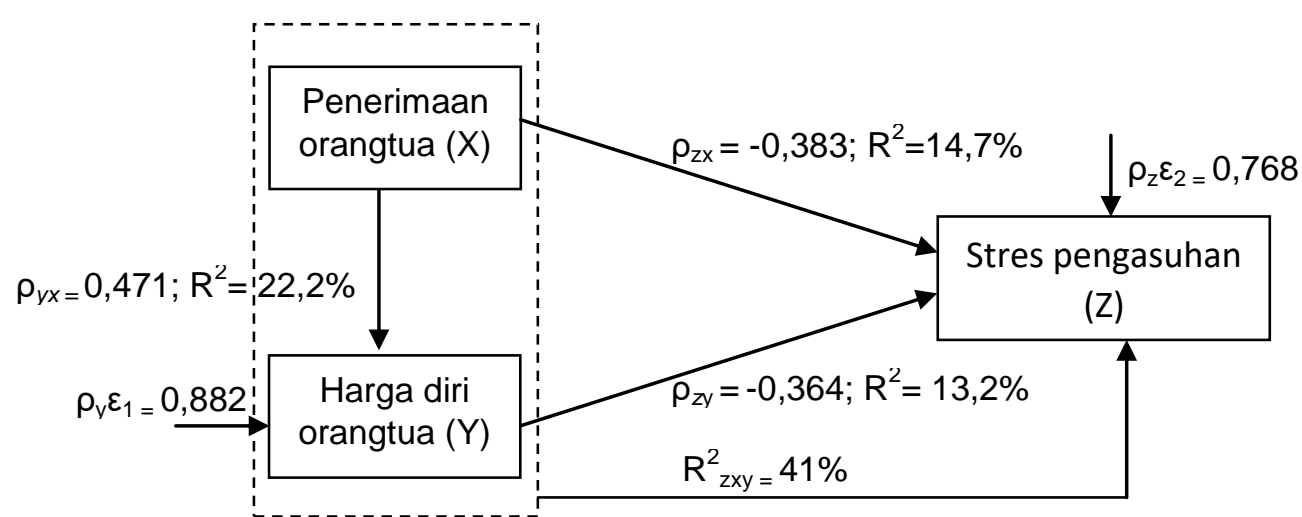

Gambar 2. Hubungan Kausal Empiris Variabel X,Y dengan Z 
Tabel dibawah ini merangkum dekomposisi koefisien jalur antara penerimaan orangtua, harga diri orangtua, dan stres pengasuhan dalam merawat anak retardasi mental.

Tabel 9. Dekomposisi Koefisien Jalur Hubungan Langsung, Hubungan Tidak Langsung, dan Hubungan Total Antar Variabel

\begin{tabular}{lccc}
\hline \multicolumn{1}{c}{ Hubungan Variabel } & \multicolumn{2}{c}{ Hubungan Kausal } \\
\cline { 2 - 3 } & Langsung & Tidak Langsung & Total \\
\cline { 2 - 3 } & & Melalui Y & \\
\hline $\begin{array}{l}\text { Penerimaan Orangtua (X) terhadap Harga } \\
\text { Diri Orangtua (Y) }\end{array}$ & 0,471 & - & 0,471 \\
\hline $\begin{array}{l}\text { Penerimaan Orangtua (X) terhadap Stres } \\
\text { Pengasuhan (Z) }\end{array}$ & $-0,383$ & 0,171 & $-0,554$ \\
\hline $\begin{array}{l}\text { Harga Diri Orangtua (Y) terhadap Stres } \\
\text { Pengasuhan (Z) }\end{array}$ & $-0,364$ & - & $-0,364$ \\
\hline $\begin{array}{l}\text { Penerimaan Orangtua (X) \& Harga Diri } \\
\text { Orangtua (Y) terhadap Stres Pengasuhan } \\
(Z)\end{array}$ & 0,410 & - & 0,410 \\
\hline
\end{tabular}

Sumber: data primer, 2016

\section{PEMBAHASAN}

Hubungan Tidak Langsung Penerimaan Orangtua terhadap Stres Pengasuhan Merawat Anak Retardasi Mental melalui Pembentukan Harga Diri Orangtua

Stres yang dialami orangtua berhubungan dengan penerimaan terhadap anak. Orangtua dengan penerimaan yang baik terhadap anak akan mampu menciptakan lingkungan yang positif dalam keluarga, dan mampu menerima kondisi anak dengan kekurangan atau keterbatasan yang dimiliki. Dalam hal ini orangtua menyadari tuntutan yang diberikan kepada anak yang akan disesuaikan dengan kemampuan anak. Dengan memiliki harapan yang realistis terhadap anak akan membuat orangtua lebih mampu beradaptasi selama merawat anak dengan retardasi mental.

Berdasarkan hasil analisis data penelitian menggunakan analisis jalur (path analysis) didapatkan bahwa secara tidak langsung penerimaan orangtua berhubungan secara signifikan dengan stres pengasuhan melalui pembentukan harga diri orangtua. Besarnya kontribusi tidak langsung tersebut sebesar 2,92\%.

Harga diri merupakan penilaian individu terhadap dirinya tentang kemampuan yang dimiliki, dan perasaan berharga yang dimiliki atas dirinya. Stuart (2013) menyatakan bahwa harga diri merupakan penilaian individu tentang nilai diri pribadi yang didapat melalui analisis antara kesesuaian perilaku dan ideal diri. Harga diri yang tinggi berhuungan dengan tinngkat kecemasan yang rendah (Stuart, 2013). Pernyataan ini sejalan dengan studi oleh Lisnayanti dkk (2015) yang menunjukkan bahwa harga diri orangtua yang semakin tinggi, maka tingkat kecemasan yang dialami dalam merawat anak dengan retardasi mental semakin rendah. Kecemasan yang dialami orangtua menggambarkan adanya stres 
pengasuhan selama merawat anak dengan retardasi mental.

Adanya hubungan secara tidak langsung antara variable penerimaan orangtua dengan stres pengasuhan melalui pembentukan harga diri orangtua menunjukkan bahwa harga diri menjadi mediasi bagi penerimaan orangtua terhadap munculnya stres pengasuhan. Hal ini berarti bahwa meskipun orangtua menunjukkan sikap penerimaan kepada anak retardasi mental, tidak menutup kemungkinan akan mengalami stres pengasuhan selama merawat anak retardasi mental apabila tidak didukung dengan harga diri yang positif.

Cara individu berperilaku dalam lingkungannya dipengaruhi oleh harga diri. Individu dengan harga diri yang tinggi akan menghadapi lingkungan secara aktif dan dapat beradaptasi dengan efektif, serta cenderung merasa aman. Sebaliknya individu dengan harga diri yang rendah memilliki kecenderungan negatif dalama melihat lingkungannya dan menganggap hal tersebut sebagai suatu ancaman bagi dirinya ancaman (Yoseph, 2014). Individu yang cenderung menilai diri lemah, tidak berharga, dan tidak mampu akan mudah mengalami frustasi dan sulit menyesuaikan dengan lingkungan, sehingga akan menyebabkan individu mengalami stres.

Orangtua dengan harga diri tinggi akan memiliki keyakinan bahwa dirinya mampu dalam merawat anak dengan retardasi mental, merasa berharga dan bisa diterima oleh lingkungan sosialnya. Dengan demikian orangtua akan memilliki kemampuan lebih adaptif dalam menghadapi berbagai masalah yang dialami selama merawat anak retardasi mental.

\section{SIMPULAN}

Penerimaan orangtua berhubungan secara langsung terhadap harga diri orangtua dengan kontribusi 22,2\%; Penerimaan orangtua berhubungan secara langsung terhadap stres pengasuhan dengan kontribusi negatif sebesar 14,7\%; Harga diri orangtua berhubungan secara langsung terhadap stres pengasuhan dengan kontribusi negatif sebesar 13,2\%. Besar hubungan tidak langsung antara penerimaan terhadap stress pengasuhan melalui harga diri orangtua adalah sebesar $2,92 \%$.

\section{SARAN}

Stres pengasuhan dalam merawat anak retardsi mental dapat diminimalkan dengan cara meningkatkan penerimaan orangtua terhadap anak, sehingga orangtua bisa menerima kondisi anak apa adanya. Disamping itu orangtua dengan penilaian diri yang positif mampu membuat orangtua beradaptasi dengan baik terhadap berbagai stressor yang dialami selama merawat anak dengan retardasi mental.

Untuk penelitian selanjutnya disarankan menggunakan pendekatan penelitian yang berbeda dengan memperluas cakupan responden agar hasil penelitian dapat digeneralisasikan dan perlu dilakukan penelitian dengan memberikan intervensi dalam mengatasi stress pengasuhan.

\section{DAFTAR PUSTAKA}

Abidin, R. R. (1992). Parenting Stress Index, Third Edition: Professional Manual. Odessa, FL: Psychological Assessment Resources, Inc. 
Ahern, Lisa S. (2004). Psychometric properties of the parenting stress index - short form. Diakses dari http//respiratory.lib.ncsu.edu/ir/ha ndle/1840.16/2765.

Bekhet A., Johnson N., \& Zauszniewski J. (2012) Resiliencein family members of persons with autism spectrum disorder: a review of the literature Issues in Mental Health Nursing. 33,650-6.

Bernard, Michael E. (2014). The Strength of Self-Acceptance: Theory, Practice and Research. Melbourne: Springer science \& bussiness media

Berry, JD, \& Jones, W,H, (1995) The Parental Stress Scale : initial psychometric evidence. Journal of Social and Personal Relationships. 12, $463-472$.

Coopersmith, S. (1967). The Antecedents of Self-esteem. San fransisco: W. H Freeman \& co.

Craig, Francesco, et al. (2016). Parenting stress among parents of children with Neurodevelopmental Disorders. Psychiatry Research, vol. 242. 121-129.

Deater, Deckard K. (2004). Parenting stress. CT: Yale university press.

Elford, Lauren M., (2015) "Mothers' Lived Experience of Parenting an Infant/Young Child with Special Needs in a Rural Context". University of Western Ontario Electronic Thesis and Dissertation Repository. Paper 2688.

Ferrell, Lisa G. (2003). A Comparison of an Intensive 4-Week Format of The Landreth 10-Week Filial Therapy Training Model With The Traditional Landreth 10Week Model of Filial Therapy. Disertasi. University of North Texas.
Glenn. (2014). Using Online Health Communication to Manage Chronic Sorrow: Mothers of Children with Rare Disease Speak. Disertasi. George Mason University.

Green, Sara Eleanor. (2004). The impact of stigma on maternal attitudes toward placement of children with disabilities in residential care facilities. Social Science \& Medicine 59: 799-812.

Green, Sara Eleanor. (2007). "We're tired, not sad": Benefits and burdens of mothering a child with a disability. Social Science \& Medicine 64: 150-163.

Hidangmayun \& Khadi (2012). Parenting stress of normal and mentally challenged children. Karnataka J. Agric. Sci.,25 (2) : (256-259).

Hurlock, E. B. (2007). Psikologi Perkembangan : suatu Pendekatan Sepanjang Rentang kehidupan (terjemahan: Istiwidayati). Jakarta: Erlangga.

Jamison, et al. (2006). Disease control priorities in developing countries, Washington DC: the international bank for Reconstruction and Development/ The World Bank.

Johnston, Cindy. (2003). Factors associated with parenting stress in mother of children with fragile $\mathrm{X}$ syndrome. Journal of Developmental and Behavioral Pediatrics. Vol 24 (4): 267- 275.

Karasavvidis, et al., (2011). Review paper: Mental retardation and parenting stress. International Journal of caring Sciences.

Khaleque, A. \& Rohner, R. P. (2002). Reliability of measures assessing the relation between perceived parental acceptance-rejection and psychological adjustment: A meta-analysis of cross-cultural 
and intracultural studies. Journal of Cross-Cultural Psychology: 33, 86-98.

Lee J. (2013). Maternal stress, wellbeing, and impaired sleep in mothers of children with developmental disabilities: a literature review. Research in Developmental Disabilities; 34(11):4255-73.

Lestari,Sri. (2012). Psikologi Keluarga: Penanaman Nilai dan Penanganan Konflik Dalam Keluarga. Jakarta : Kencana Prenada Media Group.

Lisnayanti, dkk. (2015). Hubungan tingkat harga diri (self-esteem) dengan tingkat ansietas orang tua dalam merawat anak tunagrahita Di SDLB C Negeri Denpasar. Coping Ners Journal. 3(2): 15 21.

Maslim, Rusdi. 2013. Diagnosis Gangguan Jiwa: Rujukan Ringkas PPDGJ-III. Jakarta: bagian ilmu Kedokteran Jiwa FK Unika Atmajaya.

Maulik, et al. (2011). Research in Developmental Disabilities. 32: $419-436$.

Maulina \& Sutatminingsih (2005). Stres ditinjau dari harga diri pada ibu yang memiliki anak penyandang retarasi mental. Psikologia. 1(1): 11-18.

McKeever, Patricia and Miller. (2004). Mothering children who have disabilities: a Bourdieusian interpretation of maternal practices. Social Science \& Medicine 59: 1177-1191.

McKenzie, et al. (2012). The Evaluation of a screening tool for children with an intellectual disability. Research in Developmental Disabilities. 33: $1068-1075$.
McNally, Anna \& Mannan, Hasheem. (2013). Perception of caring for children with disabilities: experiences from Moshi, Tanznia. African Journal of Disability 2(1), Art. \#21, 10 pages.

Mirza, et.al. (2009). Community management of intellectual disabilities in Pakistan: a mixed method study. Journal of Intellectual Disability Research. 53 (6): $559-570$.

Mohan, R., \& Kulkarni, M. (2018). Resilience in Parents of Children with Intellectual Disabilities. Psychology and Developing Societies, 30(1), 1943. https://doi.org/10.1177/09713 $\underline{33617747321}$

Nasir dan Muhith. (2011). Dasardasar Keperawatan Jiwa: Pengantar dan Teori. Jakarta: Salemba Medika.

National Safety Council. (2004). Manajemen Stres. Jakarta: EGC

Ntswane, AM \& Rhyn, L.van. (2007). The life-world of mothers who care for mentally retarded children: the Katutura township experience. Curationis. 30 (1): 85 $-96$.

Rohner, R.P., Khaleque A., Cournoyer, David E. (2007). Introduction to parental acceptance - rejection theory, methods, evidence and implication. Human Development and Family Studies of University of Connecticut. Diunduh dari www.cspar.uconn.edu/intro_parth eory.html.

Rohner. (2012). Introduction to parental acceptance - rejection theory, methods, evidence and implication. Human Development and Family Studies of University of Connecticut. 
Sadock, Benjamin J \& Sadock, Virginia A. (2010). Buku Ajar Psikiatri Klinis. Jakarta: EGC.

Santrock, John W. (2005). Children Development. New York: Mc. Graw Hill.

Somantri, Sutjihati. 2007. Psikologi Anak Luar Biasa. Bandung: PT Refika Aditama. 103.

Stuart, G. W \& Lararia, M. T. (2005). Principles and Practice of Psychiatric Nursing. (8th). St. Louis: Mosby.

Stuart, G. W. (2013). Principles and Practice of Psychiatric Nursing. (10th). St. Louis: Mosby.

Sularyo, Titi S. \& Kadim, M.(2000). Retardasi Mental. Sari Pediatri. 2(3): 170 -177.

Tavakolizadeh, J. et al. (2012). The effect of rational-emotional training on mothers' mental health condition of children with mental retardation. Procedia - Social and Behavioral Sciences 69: 649 658.

Townsend, M. C. (2013). Essentials of Psychiatric Mental Health Nursing. 6th Edition. Philadelphia: F. A. Davis Company.

Walker, Alexis Philbin. (2000). Parenting Stress: A Comparison of Mothers and Fathers of Disabled And Non-Disabled Children. Disertasi. University of North Texas.

Woodman, Ashley C, et al. (2015). Parenting stress and child behavior problems within families of children with developmental disabilities: Transactional relations across 15 years. Research in Developmental Disabilities. Vol.36. 264-276. Elsevier. 